\title{
Optimum Design of a Compound Helicopter
}

\author{
Hyeonsoo Yeo \\ Wayne Johnson \\ Aeroflightdynamics Directorate (AMRDEC) \\ U.S. Army Research, Development, and Engineering Command \\ Ames Research Center, Moffett Field, California \\ Flight Vehicle Research and Technology Division \\ NASA Ames Research Center \\ Moffett Field, California
}

\begin{abstract}
A design and aeromechanics investigation was conducted for a 100,000-lb compound helicopter with a single main rotor, which is to cruise at 250 knots at $4000 \mathrm{ft} / 95 \mathrm{deg} F$ condition. Performance, stability, and control analyses were conducted with the comprehensive rotorcraft analysis CAMRAD II. Wind tunnel test measurements of the performance of the H-34 and UH-1D rotors at high advance ratio were compared with calculations to assess the accuracy of the analysis for the design of a high speed helicopter. In general, good correlation was obtained when an increase of drag coefficients in the reverse flow region was implemented. An assessment of various design parameters (disk loading, blade loading, wing loading) on the performance of the compound helicopter was conducted. Lower wing loading (larger wing area) and higher blade loading (smaller blade chord) increased aircraft lift-to-drag ratio. However, disk loading has a small influence on aircraft lift-to-drag ratio. A rotor parametric study showed that most of the benefit of slowing the rotor occurred at the initial 20 to $30 \%$ reduction of the advancing blade tip Mach number. No stability issues were observed with the current design. Control derivatives did not change significantly with speed, but the did exhibit significant coupling.
\end{abstract}

\section{Notation}

\begin{tabular}{ll}
$\mathrm{A}_{\mathrm{L}}$ & rotor disk area \\
$\mathrm{C}_{\mathrm{L}}$ & rotor lift coefficient \\
$\mathrm{C}_{\mathrm{P}}$ & rotor power coefficient \\
$\mathrm{C}_{\mathrm{P}_{\mathrm{i}}}$ & rotor induced power coefficient \\
$\mathrm{C}_{\mathrm{P}_{\mathrm{O}}}$ & rotor profile power coefficient \\
$\mathrm{C}_{\mathrm{T}}$ & rotor thrust coefficient \\
$\mathrm{C}_{\mathrm{W}}$ & weight coefficient \\
$\mathrm{C}_{\mathrm{X}}$ & rotor propulsive force coefficient \\
$\mathrm{D} / \mathrm{q}$ & airframe drag divided by dynamic pressure \\
$\mathrm{L} / \mathrm{D}=\mathrm{WV} / \mathrm{P}$ & aircraft effective lift-to-drag ratio \\
$\mathrm{M}$ & Mach number \\
$\mathrm{M}_{\mathrm{at}}$ & advancing tip Mach number \\
$\mathrm{P}$ & aircraft power \\
$\mathrm{R}$ & rotor radius \\
$\mathrm{S}$ & wing area \\
$\mathrm{V}$ & flight speed \\
$\mathrm{W}$ & gross weight \\
$\mathrm{W} / \mathrm{A}$ & disk loading \\
$\mathrm{W} / \mathrm{S}$ & wing loading \\
$\alpha_{s}$ & shaft tilt angle (positive for rearward tilt) \\
$\alpha_{w}$ & wing incidence angle \\
$\mu$ & advance ratio \\
$\mathrm{v}_{\beta}$ & blade fundamental flap frequency \\
$v_{\zeta}$ & blade fundamental lag frequency \\
$\sigma$ & solidity (thrust weighted) \\
\hline
\end{tabular}

Presented at the Heli Japan 2006 AHS International Meeting on Advanced Rotorcraft Technology and Lift Saving Activities, Nagoya, Japan, November 15-17, 2006.

\section{Introduction}

Recently, the NASA Heavy Lift Rotorcraft Systems Investigation was conducted to identify candidate configurations for a large civil VTOL transport that is technically promising and economically competitive [1]. The vehicle is required to carry 120 passengers over a range of 1200 nautical miles and cruise at 350 knots at an altitude of 30,000 ft. A Large Civil Tandem Compound (LCTC) helicopter was designed as one of the candidate configurations to meet this NASA 15-year notional capability [2]. This study also revealed the need to further investigate the aeromechanics issues of a compound helicopter.

The compound helicopter is a method of achieving high speed capability while retaining the hover advantages of a helicopter. In general, the lifting and propulsive force capabilities of a helicopter rotor decrease with forward speed as a result of asymmetric flow conditions encountered by the rotor. The compound helicopter circumvents the rotor lift limit by adding wings to the fuselage (lift compounding) and the rotor propulsive limit by adding additional propulsive devices (propulsive thrust compounding). The compound helicopter investigated in this paper is defined as a helicopter with both a wing and auxiliary propulsion (fully compounding). To maintain low rotor drag at high speed, it is necessary to slow the rotor, in part to minimize the compressible drag rise on the advancing blade. 
In this paper, a design and aeromechanics investigation was conducted for a 100,000-lb compound helicopter with a single main rotor, which is to cruise at 250 knots at $4000 \mathrm{ft} / 95 \mathrm{deg} \mathrm{F}$ condition (Fig. 1). In contrast, the LCTC [2] was designed for much higher speed and altitude. This paper presents the rotor performance correlation at high speed and the results of the compound helicopter design investigation. A parametric study was conducted to understand the effects of design parameters on the performance of the aircraft. Stability and control issues are also investigated.

\section{CAMRAD II Modeling}

Performance, loads, and stability analyses were conducted with the comprehensive rotorcraft analysis CAMRAD II [3]. CAMRAD II is an aeromechanics analysis of rotorcraft that incorporates a combination of advanced technologies, including multibody dynamics, nonlinear finite elements, and rotorcraft aerodynamics. The trim task finds the equilibrium solution for a steady state operating condition, and produces the solution for performance, loads, and vibration. The flutter task linearizes the equations about the trim solution, and produces the stability results. The aerodynamic model includes a wake analysis to calculate the rotor nonuniform induced-velocities, using rigid, prescribed, or free wake geometry. CAMRAD II has undergone extensive correlation of performance and loads measurements on helicopters [4-6].

A complete aeroelastic model was developed for the analysis of the compound helicopter. The comprehensive analysis modeled the auxiliary propulsion as forces applied to the airframe. Rotor/wing interference was accounted for using a vortex wake model for both the rotor and the wing. For all the calculations made in this study, an elastic blade model was used, scaled from the LCTC blade design. Rotor performance was calculated using nonuniform inflow with prescribed wake geometry in high speed cruise and free wake geometry in hover.

In cruise, the aircraft was trimmed using lateral stick to the ailerons, longitudinal stick to the elevator, pedal to differential propeller thrust; plus propeller thrust, and aircraft pitch and roll angles. Rotor collective pitch angle was set to values optimized for cruise performance (optimized rotor thrust). In addition to three force and three moment equilibrium of the aircraft, rotor hub roll and pitch moments were trimmed to zero (for load control) using rotor cyclic pitch; thus there were eight trim variables for cruise.

\section{Rotor Performance Correlation at High Speed}

The ability to accurately predict the performance of a helicopter is essential for the design of future rotorcraft. It is necessary to assess the accuracy and reliability of these prediction methods, with the ultimate goal of providing the technology for timely and cost-effective design and development of new rotors.

Wind tunnel test data of the full-scale $\mathrm{H}-34$ rotor [7] and UH-1D rotor [8] obtained in the late 1960's provide a set of test conditions at high advance ratios. A fullscale $\mathrm{H}-34$ articulated rotor with zero twist blades was tested in the NASA Ames 40- by 80 -Foot Wind Tunnel. Tunnel speed and rotor rotational speed were adjusted to obtain the desired advance ratio and advancing tip Mach number. At each combination of shaft tilt angle and collective pitch, the cyclic pitch was adjusted to minimize first harmonic blade flapping. A full-scale UH$1 \mathrm{D}$ teetering rotor with $-1.42 \mathrm{deg}$ twist blades, reduced in diameter to 34 feet, was tested in the NASA Ames 40- by 80 -Foot Wind Tunnel. The test procedure was same as for the H-34 rotor test. Both rotors used an NACA 0012 airfoil.

Rotor performance calculations with CAMRAD II are compared with the wind tunnel test data in Figs. 2 and 5. Figure 2 shows the rotor induced power plus profile power versus rotor lift for the H-34 rotor for three different shaft tilt angles. The wind tunnel data for rotor induced power plus profile power were obtained from the total rotor power coefficient and rotor propulsive coefficient measurements; $\mathrm{C}_{\mathrm{P}_{\mathrm{i}}}+\mathrm{C}_{\mathrm{P}_{\mathrm{O}}}$ $=\mathrm{C}_{\mathrm{P}}-\mathrm{C}_{\mathrm{X}} \mu$. Rotor performance was calculated using nonuniform inflow with free wake geometry and unsteady aerodynamics, but a dynamic stall model was not used. The rotor induced plus profile power increases as advance ratio increases for the same rotor lift and as rotor lift increases for the same advance ratio. The analysis shows, in general, good correlation with the measurements. Underprediction of rotor power at high rotor lift was observed. It appears that the current analysis or airfoil table used has optimistic stall characteristics.

The good correlation in Fig. 2 was obtained by modifying drag coefficient in the NACA 0012 airfoil table. Figure 3 shows the effect of airfoil drag coefficient on the $\mathrm{H}$ 34 rotor performance at $\alpha_{s}=0 \mathrm{deg}$. The analysis with the existing NACA 0012 airfoil table shows good correlation at $\mu=0.46$. However, the analysis underpredicted the required power at higher advance ratios and the underprediction became larger as the advance ratio increases. This trend appears due to lower drag coefficients in the reverse flow region, because the reverse flow region increases proportional to $\mu^{2}$. The drag coefficients of the airfoil table were uniformly 
increased by 0.1 in the reverse flow region $(-180 \leq \alpha$ $\leq-90,90 \leq \alpha \leq 180$ ), resulting in significantly better correlation. The actual airfoil drag characteristics in the reverse flow region are undoubtedly more complicated than implied by this simple correction. In particular, a strong dependence on Mach number is likely. In the NACA 0012 airfoil table used, there is no dependence on Mach number in the reverse flow region.

Figure 4 shows the effect of wake modeling on the $\mathrm{H}$ 34 rotor performance at $\alpha_{s}=0 \mathrm{deg}$. Rotor performance was calculated with prescribed wake geometry and the result was compared with that with free wake geometry. The wake is quickly convected from the rotor disk in high speed condition. Thus, there is no difference in the rotor performance calculations between the two wake geometries.

Figure 5 shows the rotor induced power plus profile power versus rotor lift for the UH-1D rotor for three different shaft tilt angles. Again, the drag coefficients of the NACA 0012 airfoil were uniformly increased by 0.1 in the reverse flow region. The analysis shows reasonably good correlation, considering the scatter of the measured data. There is an underprediction of rotor power at $\mu=$ 0.65 , although the same trend was not observed at $\mu=$ 0.51 and 0.76 . The reason for the observed difference is not known at present.

For conventional helicopters, the reverse flow region does not have a significant influence on rotor performance because of moderate cruise speed and low dynamic pressure in the region. However, the reverse flow region is important for high speed helicopters, such as the one considered in this study. Airfoil characteristics in the reverse flow region should be more throughly studied and validated.

\section{Aircraft Design Study}

An assessment of various compound helicopter designs was conducted in order to understand the effects of design parameters on the performance of the aircraft and to define a baseline model for an aeromechanics study. The compound helicopter configuration developed in this study is shown in Fig. 1. The aircraft has a six bladed rotor, a high wing, a horizontal tail, and two auxiliary propellers located on the wing for cruise propulsion and anti-torque in hover. State-of-the-art rotor airfoils (VR12 and SSCA09) were used for the main rotor blades. The increased drag coefficient values used for the $\mathrm{H}$ 34 and UH-1D rotor performance correlation were not incorporated into these baseline airfoils. The effect of airfoil drag coefficients on the compound helicopter was examined in the next section.
A hingeless rotor hub was used. Blade inertial and structural properties were scaled from the blade developed from the LCTC [2]. Figure 6 shows the calculated blade frequencies, at a collective pitch angle of $10 \mathrm{deg}$. At helicopter-mode tip speed, the first flap frequency was about $2.3 / \mathrm{rev}$, the first lag frequency was above $5.4 / \mathrm{rev}$, and the first torsion frequency about $6.5 / \mathrm{rev}$.

Table 1 shows the design parameters investigated. The baseline aircraft design parameters (Fig. 1) are disk loading of $\mathrm{W} / \mathrm{A}=15 \mathrm{lb} / \mathrm{ft}^{2}$, blade loading of $\mathrm{C}_{\mathrm{T}} / \sigma=$ 0.14 , and wing loading of $\mathrm{W} / \mathrm{S}=100 \mathrm{lb} / \mathrm{ft}^{2}$. This design was the optimum design for the LCTC, and is shown below to give good performance for the present aircraft. The $\mathrm{C}_{\mathrm{T}} / \sigma=0.14$ and $\mathrm{W} / \mathrm{S}=100$ are appropriate for an aircraft that unloads the rotor at a relatively low speed. The aircraft parasite drag is $\mathrm{D} / \mathrm{q}=40.5 \mathrm{ft}^{2}$. This drag value, which was obtained from historic trends [2], is higher than current turboprop aircraft, but lower than is customary in the helicopter industry. The baseline design has a wing span equal to the rotor diameter (Fig. 1). The hover tip speed is $750 \mathrm{ft} / \mathrm{sec}$, and the cruise tip speed of $502 \mathrm{ft} / \mathrm{sec}$ which gives $\mathrm{M}_{\mathrm{at}}=0.8$ at 250 knots. The advance ratio is then $\mu=0.84$ at 250 knots.

Design variations of wing loading (W/S = 100 vs 120 ), blade loading $\left(\mathrm{C}_{\mathrm{T}} / \sigma=0.14\right.$ vs 0.09$)$, and disk loading $(\mathrm{W} / \mathrm{A}=15$ vs 12) were examined. The larger disk area will give lower hover power. The larger blade area or smaller wing area correspond to loading the rotor rather than the wing. Note that $\mathrm{C}_{\mathrm{T}} / \sigma=0.09$ would be appropriate for an advanced technology helicopter, hence the rotor could carry the aircraft weight to conventional helicopter speeds.

Figures 7 through 9 show the performance results in terms of aircraft lift-to-drag ratio $\mathrm{L} / \mathrm{D}=\mathrm{WV} / \mathrm{P}$, calculated without accessory or other losses, and using a propeller efficiency of 0.86 , all for the design cruise condition of 250 knots. For each combination of disk loading, design blade loading, and wing loading, three collective angles $(-3,0$, and $3 \mathrm{deg})$ and six values for the difference between wing incidence and shaft tilt angle $\left(\alpha_{w}-\alpha_{s}=\right.$ $-4,-1,1,3,5$, and $7 \mathrm{deg}$ ) were used. The rotor RPM was 104.0 to obtain $\mathrm{M}_{\mathrm{at}}=0.8$.

Figure 7 shows the effect of wing loading (W/S $=100$ vs 120 ) on aircraft lift-to-drag ratio for $\mathrm{W} / \mathrm{A}=15$ and $\mathrm{C}_{\mathrm{T}} / \sigma=0.14$. To obtain higher wing loading, wing area was reduced by decreasing wing span for a given chord. The aircraft lift-to-drag ratio increases as the $\alpha_{w}-\alpha_{s}$ increases (wing incidence increases or rotor shaft tilts forward) up to $3 \mathrm{deg}$ for the collective angle of 0 and $3 \mathrm{deg}$ and up to $5 \mathrm{deg}$ for the collective angle of $3 \mathrm{deg}$, and then decreases. The best performance was obtained for the collective angle of 0 or $-3 \mathrm{deg}$ and $\alpha_{w}-\alpha_{s}=3$ 
deg. Lower wing loading (higher wing area) increased the aircraft lift-to-drag ratio. The smaller wing area corresponds to loading the rotor rather than the wing. A wing is a more efficient lifting device than a rotor for the current 250 knot compound helicopter, thus the larger wing area improves the aircraft performance.

Figure 8 shows the effect of blade loading $\left(\mathrm{C}_{\mathrm{T}} / \sigma=\right.$ 0.14 vs 0.09 ) on aircraft lift-to-drag ratio for W/A $=15$ and $\mathrm{W} / \mathrm{S}=100$. To obtain lower blade loading, blade area was increased by increasing blade chord for a given blade radius. Thus, solidity was increased but aspect ratio was decreased. The larger blade area corresponds to loading the rotor rather than the wing. Higher design blade loading (smaller blade chord) increased the aircraft lift-to-drag ratio because the smaller blade chord reduced rotor profile power.

Figure 9 shows the effect of disk loading $(\mathrm{W} / \mathrm{A}=15$ vs 12) on aircraft lift-to-drag ratio for $\mathrm{W} / \mathrm{S}=100$ and $\mathrm{C}_{\mathrm{T}} / \sigma=0.14$. To obtain lower disk loading, rotor diameter was increased, but to maintain the same blade loading for the increased rotor diameter, blade chord was decreased. Thus, the blade area are identical for the two cases. Disk loading has a small influence on the aircraft performance, although it will have an impact on the rotor weight. Because the smaller blade chord increased the aircraft lift-to-drag ratio as shown in Fig. 8, the larger rotor diameter must have decreased the aircraft lift-todrag ratio as much as the improved aircraft lift-to-drag ratio by the smaller chord. The same blade area appears to result in the same aircraft performance.

The optimum required rotor shaft power and optimum lift sharing between the rotor and wing were investigated for the baseline aircraft $\left(\mathrm{W} / \mathrm{A}=15, \mathrm{C}_{\mathrm{T}} / \sigma=0.14, \mathrm{~W} / \mathrm{S}\right.$ $=100)$ at cruise speed of 250 knots and the results are shown in Fig. 11 through 10. Figure 10 shows the rotor shaft power for the baseline aircraft. The rotor power increases as $\alpha_{w}-\alpha_{s}$ increases. The required rotor power at the optimum aircraft lift-to-drag ratio occurred with a small, positive shaft power to the rotors: between 500 and $1000 \mathrm{HP}$. With the rotor in autorotation (zero rotor shaft power), the rotor thrust was large, hence the total rotor drag larger and the aircraft L/D somewhat smaller.

Figure 11 shows the rotor and wing lift for the baseline aircraft. As the $\alpha_{w}-\alpha_{s}$ increases, the rotor lift decreases and wing lift increases. The higher collective angle increases the rotor lift and decreases wing lift. The optimum lift sharing between the rotor and wing for the baseline aircraft is: the rotor carries $8-9 \%$ of the aircraft gross weight and the wing carries $91-92 \%$ of the aircraft gross weight. The optimum lift sharing between the rotor and wing varied depending on disk loading, design blade loading, and wing loading. The rotor needs to carry more lift as the wing loading increases and the design blade loading decreases as shown in Fig. 12.

Performance results for the baseline aircraft are shown in Figs. 13 and 14. The hover figure of merit of an isolated rotor is calculated with $750 \mathrm{ft} / \mathrm{sec}$ tip speed and the result is shown in Fig. 13. The calculation was conducted using nonuniform inflow with free wake geometry. The figure of merit decreases as the thrust increases. The figure of merit is around 0.78 at the design thrust $\left(\mathrm{C}_{\mathrm{T}} / \sigma=0.1484\right.$ with assumed $6 \%$ hover download). Figure 14 shows the aircraft lift-to-drag ratio with different airspeeds. The calculation was conducted using nonuniform inflow with prescribed wake geometry. The airspeed was varied from 200 to 350 knots; with the rotor tip speed linearly decreased from hover. The aircraft lift-to-drag ratio decreases as airspeed goes up. At the design cruise speed (250 knots), the aircraft lift-to-drag ratio is 7.69 .

\section{Rotor Parametric Study}

This section describes a parametric study of key rotor design parameters conducted with the comprehensive analysis. The baseline design was disk loading of 15 , design blade loading of 0.14 , wing loading of 100 , collective angle of $0 \mathrm{deg}$, and $\alpha_{w}-\alpha_{s}$ of $3 \mathrm{deg}$.

The blade twist was varied to obtain balanced hover and cruise performance. The hover condition was $750 \mathrm{ft} / \mathrm{sec}$ tip speed, $\mathrm{C}_{\mathrm{T}} / \sigma=0.1484$ (assumed 6\% download). The cruise condition was 250 knots, $502 \mathrm{ft} / \mathrm{sec}$ tip speed. The twist distribution had two linear segments, inboard (0.0R to $0.5 \mathrm{R})$ and outboard $(0.5 \mathrm{R}$ to $1.0 \mathrm{R})$. Figure 15 presents the results for twist variation. For each value of outboard twist $(-15,-12,-9,-6,-3$, and $0 \mathrm{deg})$, the inboard twist values are $-3,0,3$, and $6 \mathrm{deg}$. A large negative twist improves hover performance, but the zero twist gives the best cruise performance. The design twist of $0 \mathrm{deg}$ inboard and -12 deg outboard was selected based on the hover-cruise compromise. The result shows that the aircraft lift-to-drag ratio varies 0.64 and the hover figure of merit varies 0.115 within the twist range investigated. These variations are larger for the current design than those for the LCTC shown in Fig. 16 (aircraft lift-todrag ratio varies 0.37 and hover figure of merit varies 0.069) developed in the Ref. 2. Thus, the blade twist is more important parameter for the current design than the LCTC. However, the aircraft lift-to-drag is less sensitive to the inboard twist change for fixed outboard twist. Thus, the benefit of bi-linear twist diminished for the current design compared with the LCTC.

The rotor advancing tip Mach number was varied from 0.5 to 0.9 to investigate the effects of the rotor rotational speed on the high speed cruise (250 knots) performance, 
as shown in Fig. 17. It should be noted that the rotor advancing tip Mach number in cruise is about 1.02 with the hover tip speed. To maintain low rotor drag at high speed, it is necessary to slow the rotor. The aircraft liftto-drag ratio increases as the advancing tip Mach number decreases, reaching the maximum at $\mathrm{M}_{\mathrm{at}}=0.55$, which corresponds to $\mu=1.98$. Most of the benefit of slowing the rotor occurs at the initial 20 to $30 \%$ reduction of the advancing blade tip Mach number. The design point was found at $\mathrm{M}_{\mathrm{at}}=0.80$, which corresponds to $\mu=0.84$. This values corresponds to about $20 \%$ reduction of the advancing blade tip Mach number and 33\% reduction of the rotor tip speed from hover condition.

The blade taper ratio was varied as shown in Fig. 18. The taper model considered was linear taper with constant thrust-weighted solidity (chord at $75 \% \mathrm{R}$ ). The aircraft lift-to-drag ratio decreased as the taper was reduced. Although the taper of 1.0 produced the best aircraft liftto-drag ratio, the taper of 0.8 (tip/root chord) was selected to reduce the blade weight.

Collective pitch of the rotor was varied by $1 \mathrm{deg}$ from -3 to +3 deg to further investigate the effect of the collective pitch (rotor thrust) on the aircraft lift-to-drag ratio, as shown in Fig. 19. The aircraft performance was not sensitive to the collective angle change. The highest aircraft lift-to-drag ratio, which occurred with the -2 deg collective angle, was $0.34 \%$ higher than that with the baseline collective angle ( $0 \mathrm{deg})$. The aircraft lift-todrag ratio changed less than $2 \%$ with the collective angles investigated.

Good rotor performance correlation was obtained for the $\mathrm{H}-34$ and UH-1D rotor at high advance ratios with the increased drag coefficients of the NACA 0012 airfoil table in the reverse flow region. Most of helicopter airfoil tables have similar drag coefficients as the NACA 0012 airfoil in the reverse flow region. Figure 20 shows the effect of the airfoil drag coefficients on the compound helicopter performance. The drag coefficients in the reverse flow region were increased by 0.1 , same as the NACA 0012 airfoil case. The aircraft lift-to-drag ratio was reduced by about $6 \%$ with the increased drag coefficients at all $\alpha_{w}-\alpha_{s}$ investigated.

\section{Aeroelastic Stability}

Aeroelastic stability is a very important aspect of the design of helicopters. Stability of a compound helicopter was investigated using the baseline design as disk loading of 15 , design blade loading of 0.14 , wing loading of 100 , collective angle of $0 \mathrm{deg}$, and $\alpha_{w}-\alpha_{s}$ of $3 \mathrm{deg}$.

Figure 21 shows rotor stability calculations in level flight. Rotor tip speed was varied linearly from the hover value to the cruise value. The corresponding blade frequencies are shown in Fig. 6. Stability is, in general, insensitive to the speed. No stability issues were observed between 150 to 300 knots.

Figure 22 shows rotor stability at 250 knots with respect to blade frequency change, with the objective of examining the stability characteristics of a compound helicopter with more conventional blade frequency placements. The lines in the figure show damping scaled by magnitude. Figure 22(a) shows rotor stability with respect to the first flap frequency change. In this calculation, a flap hinge and spring stiffness were introduced to change the flap frequency to that of a conventional articulated rotor. Both the lag and torsion stiffness values were maintained same as the baseline values. The hingeless rotor blade was simulated with very stiff spring and the spring stiffness was decreased to reduce flap frequency. The baseline blade, which was scaled from the LCTC blade design, shows stable modes with the flap frequency change. Figures 22(b) and 22(c) show rotor stability with respect to the first lag and first torsion frequency change, respectively. Blade lag and torsion stiffness were reduced to obtain lower frequencies, while maintaining the baseline flap frequency. These frequency changes significantly reduced stability margin, although all the modes were stable within the frequency ranges investigated.

Figure 23 shows rotor stability with respect to the first torsion frequency change at 250 knots for a nominal articulated rotor which has the first flap frequency of $1.05 / \mathrm{rev}$ at cruise RPM. Two lag frequencies were investigated; stiff in-plain (1.14/rev) and soft in-plain $(0.71 / \mathrm{rev})$ rotor. Instability occurred at the first torsion frequency of $4.1 / \mathrm{rev}$ for the stiff in-plain rotor and $3.85 /$ rev for the soft in-plain rotor.

Figure 24 shows rotor stability (least damped mode) with respect to the first torsion frequency change at 250 knots for a nominal articulated rotor with the rotor RPM change (thus advance ratio change). Again, the two lag frequencies were investigated; stiff in-plain (1.14/rev) and soft in-plain $(0.71 / \mathrm{rev})$ rotor. In this calculation, both flap and lag stiffness values were adjusted at different rotor RPM to maintain the same frequencies in per revolution. Instability occurred, in general, at higher first torsion frequency as the advance ratio increases (rotor RPM decreases). The stability boundary is summarized in Table 2.

\section{Rotor Control}

Helicopter control requires the ability to produce forces and moments on the vehicle. The changes of hub forces and moments with respect to pilot controls are shown 
in Fig. 25 as a function of flight speed for the baseline design (high flap frequency). The calculation was carried out for fixed controls, with \pm 1 deg of collective and cyclic angle change relative to the trimmed solution. The phase shift needed for hingeless rotor control was not considered: longitudinal and lateral cyclic are sine and cosine harmonics of root pitch. Figures 25(a) and 25(b) show the hub force and moment change with respect to collective angle change. As expected, collective angle changed vertical force by about 8000 to $12,000 \mathrm{lb}$ at 175 and 300 knots, respectively. Lateral and longitudinal force change was small. A large roll moment change was observed. It is because the lift increase with the increased collective angle is concentrated on the advancing side due to a large reverse flow region on the retreating side.

Figures 25(c) and 25(d) show the hub force and moment change with respect to lateral cyclic angle change. Hub force change was small. There is a large pitch moment change, as expected.

Figures 25(e) and 25(f) show the hub force and moment change with respect to longitudinal cyclic angle change. The results are quite similar to the hub force and moment change with respect to collective angle. There are smaller changes in vertical force and roll moment with the longitudinal cyclic change than the collective change.

In summary, for this hingeless rotor the control derivatives did not change much with speed, but did exhibit significant coupling.

\section{Conclusions}

A design and aeromechanics investigation was conducted for a $100,000 \mathrm{lb}$ compound helicopter with a single main rotor, which is to cruise at 250 knots at 4000 $\mathrm{ft} / 95$ deg $\mathrm{F}$ condition. Performance, stability, and control analyses were conducted with the comprehensive rotorcraft analysis CAMRAD II.

Wind tunnel test measurements of the performance of the H-34 and UH-1D rotors at high advance ratio were compared with calculations to assess the accuracy of the analysis for the design of a high speed helicopter. In general, good correlation was obtained when an increase of drag coefficients $\left(\Delta c_{d}=0.1\right)$ in the reverse flow region was implemented.

An assessment of various design parameters (disk loading, design blade loading, wing loading) on the performance of the compound helicopter were made.

1. Lower wing loading (larger wing area) and higher design blade loading (smaller blade chord) increased aircraft lift-to-drag ratio. However, disk loading has a small influence on aircraft lift-to-drag ratio.

2. For the baseline design (W/A $=15, \mathrm{C}_{\mathrm{W}} / \sigma=0.14$, $\mathrm{W} / \mathrm{S}=100$ ), the optimum lift sharing between the rotor and wing is: rotor carries $8-9 \%$ of gross weight and wing carries $91-92 \%$ of gross weight.

3. The optimum aircraft lift-to-drag ratio for the baseline design occurred with a small, positive shaft power to the rotors: between 500 and 1000 HP.

A rotor parametric study was conducted to investigate the effects of twist, collective, tip speed, taper, and drag coefficients on the aircraft lift-to-drag ratio.

1. Blade twist is a more important parameter on the aircraft performance for the current compound helicopter design than the compound helicopter developed in the NASA Heavy Lift Investigation.

2. Most of the benefit of slowing the rotor occurs at the initial 20 to $30 \%$ reduction of the advancing blade tip Mach number.

3. Aircraft performance is not sensitive to collective angle change.

No stability issues were observed with the current design as long as torsion frequency is kept above about 4/rev. The control derivatives did not change significantly with speed, but they did exhibit significant coupling.

\section{References}

[1] Johnson, W., Yamauchi, G. K., and Watts, M. E., "Design and Technology Requirements for Civil Heavy Lift Rotorcraft," Proceedings of the American Helicopter Society Vertical Lift Aircraft Design Conference, San Francisco, CA, January 2006.

[2] Yeo, H., and Johnson, W., "Aeromechanics Analysis of a Heavy Lift Slowed-Rotor Compound Helicopter," Proceedings of the American Helicopter Society Vertical Lift Aircraft Design Conference, San Francisco, CA, January 2006.

[3] Johnson, W., "Technology Drivers in the Development of CAMRAD II," American Helicopter Society Aeromechanics Specialist Meeting, San Francisco, CA, January 1994.

[4] Yeo, H., Bousman, W. G., and Johnson, W., "Performance Analysis of a Utility Helicopter with Standard and Advanced Rotor," Journal of the American Helicopter Society, Vol. 49, No. 3, July 2004. 
[5] Yeo, H., and Johnson, W., "Assessment of Comprehensive Analysis Calculation of Airloads on Helicopter Rotors," Journal of Aircraft, Vol. 42, No. 5, September-October 2005.

[6] Yeo, H., and Johnson, W., "Comparison of Rotor Structural Loads Calculated Using Comprehensive Analysis," Proceedings of the 31st European Rotorcraft Forum, Florence, Italy, September 2005.

[7] McCloud, J. L., Biggers, J. C., and Stroub, R. H., “An Investigation of Full-Scale Helicopter Rotors at High Advance Ratios and Advancing Tip Mach Numbers," NASA TN D-4632, July 1968.

[8] Charles, B. D., and Tanner, W. H., "Wind Tunnel Investigation of Semirigid Full-Scale Rotors Operating at High Advance Ratios," USAAVLABS TR 69-2, January 1969. 
Table 1 Compound helicopter design parameters.

(a) Parameters independent of design conditions.

\begin{tabular}{ll}
\hline \hline Operating condition (ft, deg F) & $4000 / 95$ \\
Cruise speed (knots) & 250 \\
Mission GW (lb) & 100,000 \\
Tip speed, hover (ft/sec) & 750 \\
Tip speed, cruise (ft/sec) & 502 \\
Drag D/q $\left(\mathrm{ft}^{2}\right)$ & 40.5 \\
Drag, $(\mathrm{D} / \mathrm{q}) /(\mathrm{W} / 1000)^{2 / 3}$ & 1.9 \\
Number of blades & 6 \\
Taper ratio (blade, wing) & 0.8 \\
\hline \hline
\end{tabular}

(b) Parameters dependent on design conditions.

\begin{tabular}{cllll}
\hline \hline Disk loading W/A $\left(\mathrm{lb} / \mathrm{ft}^{2}\right)$ & 15 & 15 & 12 & 12 \\
Rotor diameter $(\mathrm{ft})$ & 92.13 & 92.13 & 103.01 & 103.01 \\
\hline Blade loading $\left(\mathrm{C}_{\mathrm{W}} / \sigma\right)$ & 0.14 & 0.09 & 0.14 & 0.09 \\
Solidity & 0.0992 & 0.1543 & 0.0794 & 0.1235 \\
Chord $(75 \% \mathrm{R}, \mathrm{ft})$ & 2.39 & 3.72 & 2.14 & 3.33 \\
Aspect ratio & 19.25 & 12.38 & 24.06 & 15.47 \\
\hline Wing loading W/S $\left(\mathrm{lb}^{2} \mathrm{ft}^{2}\right)$ & 100 & 120 & & \\
Area $\left(\mathrm{ft}^{2}\right)$ & 1000 & 833 & & \\
Span $(\mathrm{ft})$ & 92.13 & 76.78 & & \\
Chord $(75 \% \mathrm{R}, \mathrm{ft})$ & 10.25 & 10.25 & & \\
Aspect ratio & 8.49 & 7.07 & & \\
\hline \hline
\end{tabular}

Table 2 Stability boundary for nominal articulated rotor $\left(v_{\beta}=1.05 / \mathrm{rev}\right)$ at 250 knots with different rotor RPM.

(a) Stiff in-plain rotor $\left(v_{\zeta}=1.14 / \mathrm{rev}\right)$.

\begin{tabular}{ccc}
\hline \hline advance ratio & rotor RPM & stability boundary (/rev) \\
\hline 0.84 & 104.0 & 3.85 \\
0.95 & 92.0 & 4.64 \\
1.10 & 80.1 & 4.45 \\
1.30 & 68.1 & 5.11 \\
\hline \hline
\end{tabular}

(b) Soft in-plain rotor $\left(v_{\zeta}=0.71 / \mathrm{rev}\right)$.

\begin{tabular}{ccc}
\hline \hline 0.84 & 104.0 & 4.11 \\
0.95 & 92.0 & 4.37 \\
1.10 & 80.1 & 4.42 \\
1.30 & 68.1 & 4.76 \\
\hline \hline
\end{tabular}



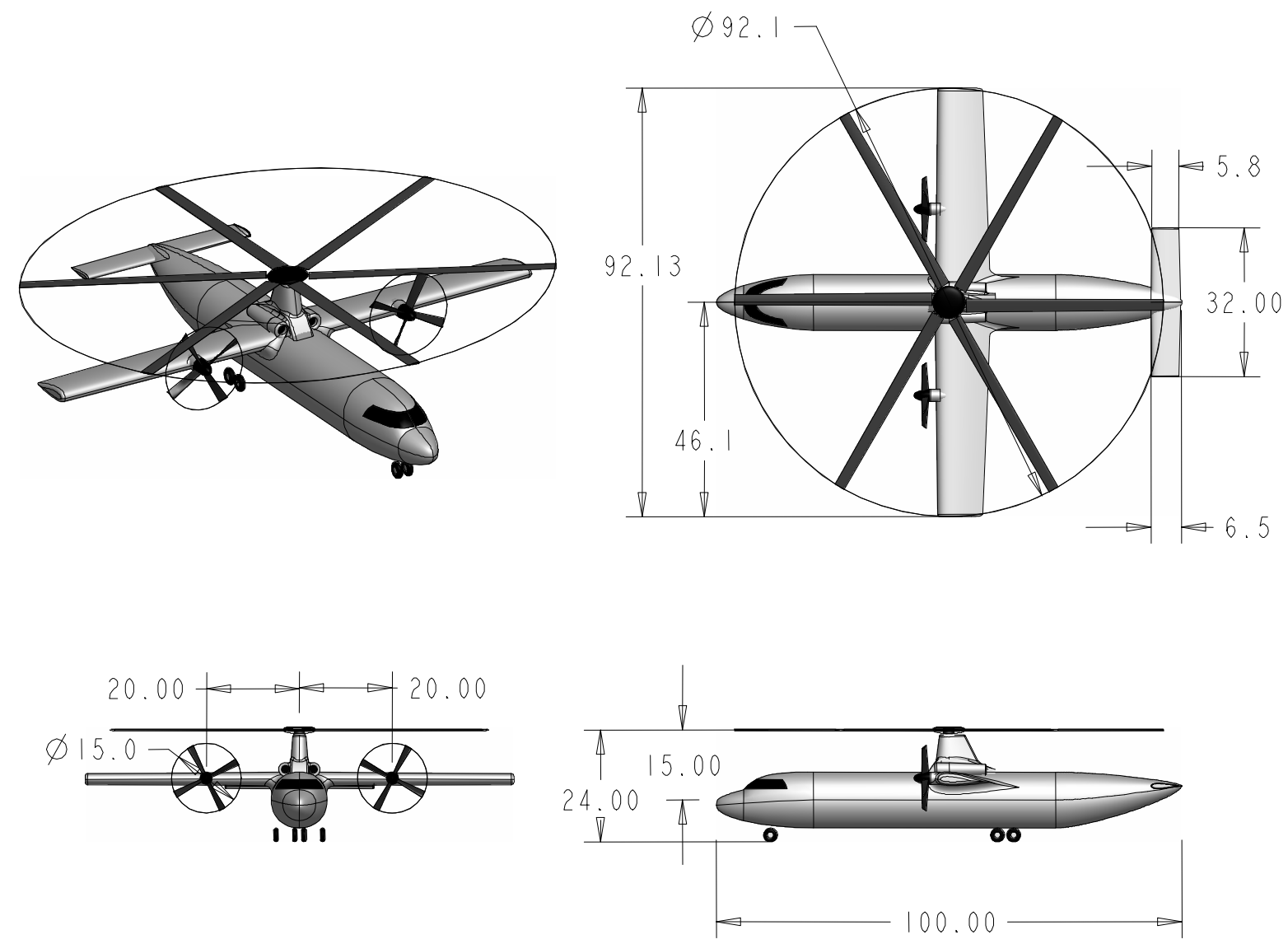

Fig. 1 Three-view of the compound helicopter - dimensions are in $\mathrm{ft}$ (courtesy Gerardo Nunez). 


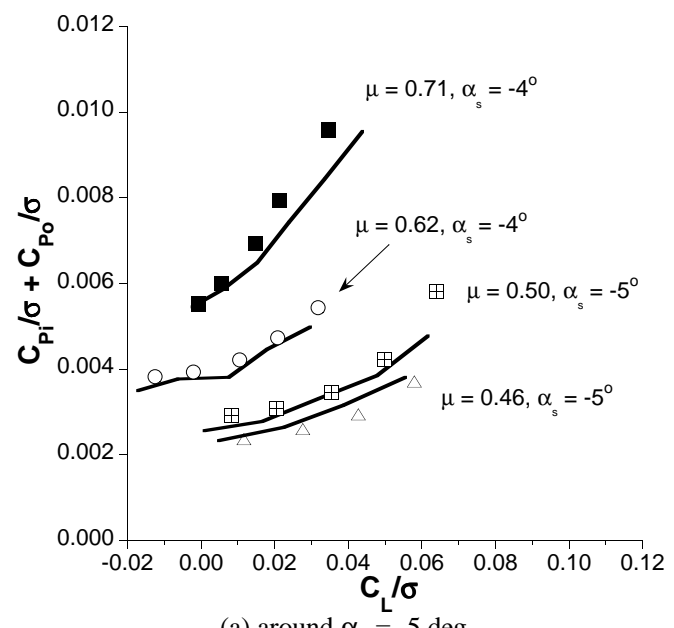

(a) around $\alpha_{s}=-5 \mathrm{deg}$

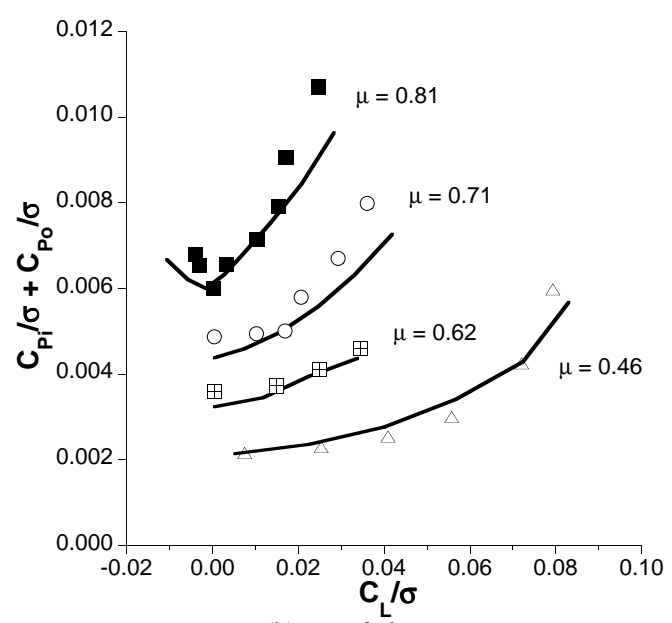

(b) $\alpha_{s}=0 \mathrm{deg}$

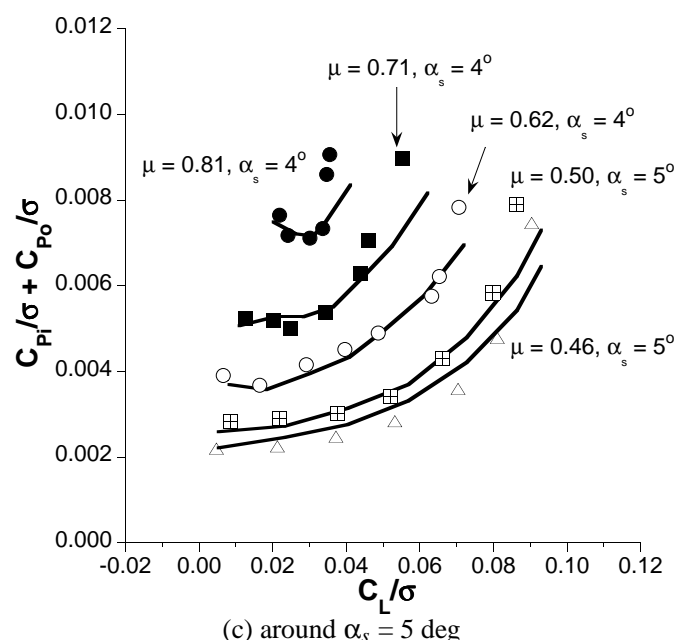

(c) around $\alpha_{s}=5 \mathrm{deg}$

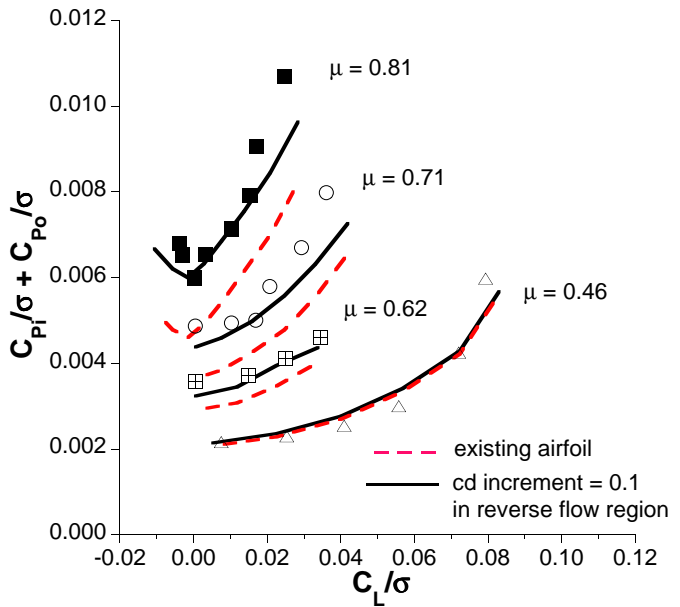

Fig. 3 Effect of airfoil drag coefficient on H-34 rotor performance at $\alpha_{s}=0 \mathrm{deg}$ (symbols: wind tunnel test, lines: analysis).

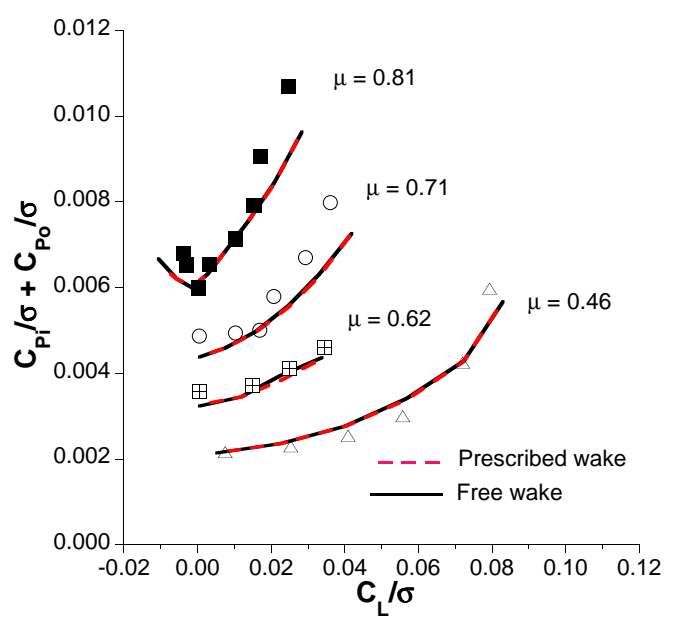

Fig. 4 Effect of wake modeling on H-34 rotor performance at $\alpha_{s}=0 \mathrm{deg}$ (symbols: wind tunnel test, lines: analysis).

Fig. 2 H-34 rotor performance correlation (symbols: wind tunnel test, lines: analysis). 


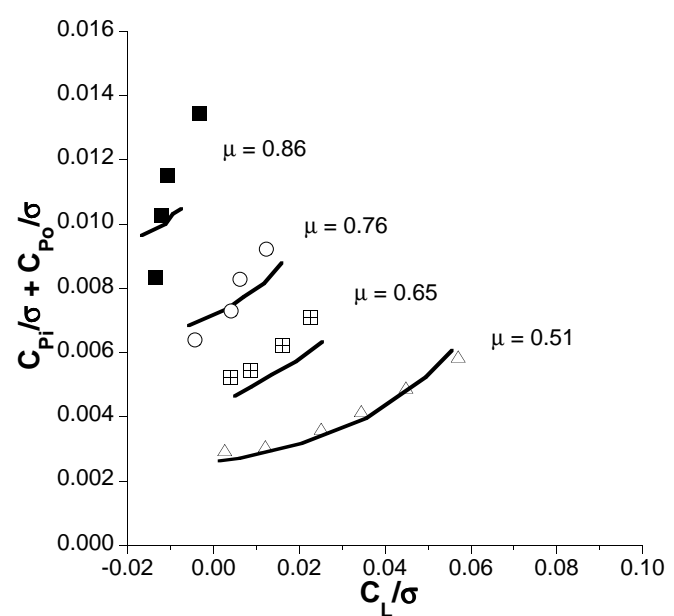

(a) $\alpha_{s}=-4 \mathrm{deg}$

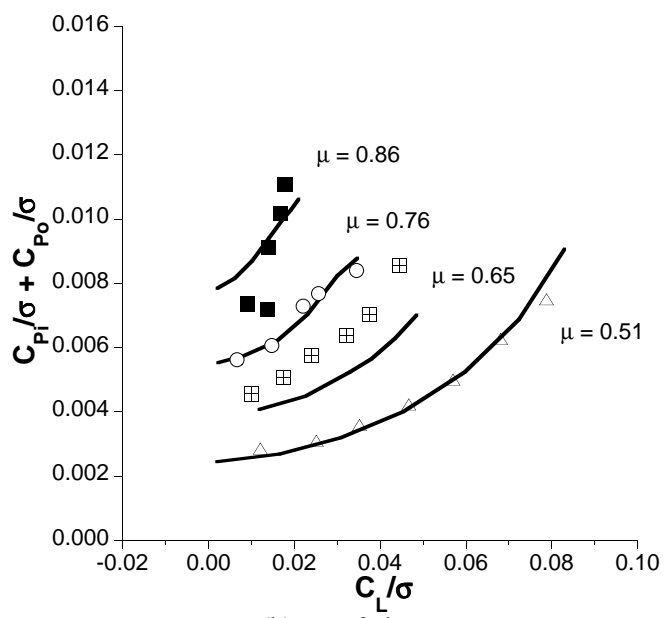

(b) $\alpha_{s}=0 \mathrm{deg}$

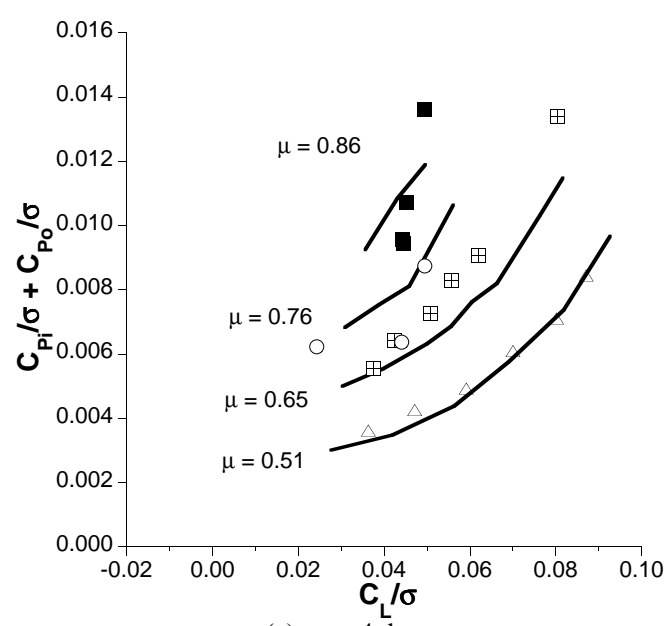

(c) $\alpha_{s}=4 \mathrm{deg}$

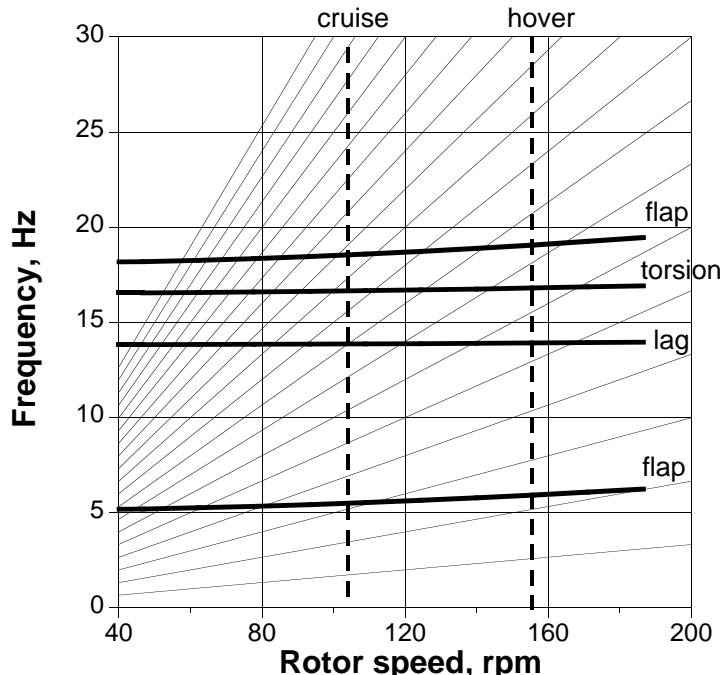

Fig. 6 Blade frequencies (collective $=10 \mathrm{deg}$ ).

Fig. 5 UH-1D rotor performance correlation (symbols: wind tunnel test, lines: analysis). 


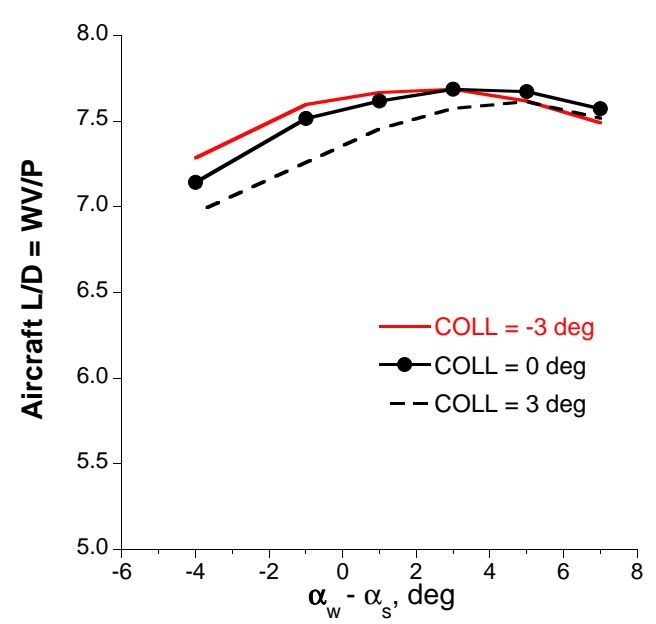

(a) Wing loading $(\mathrm{W} / \mathrm{S})=100$

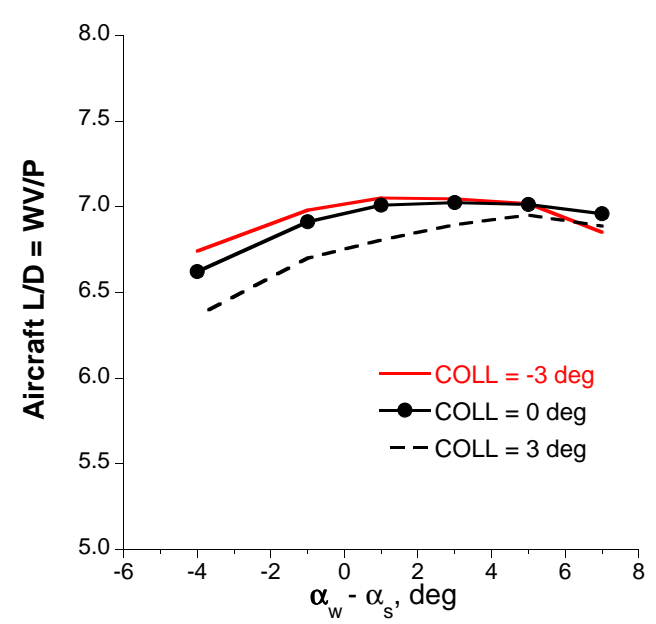

(b) Wing loading $(\mathrm{W} / \mathrm{S})=120$

Fig. 7 Effect of wing loading on aircraft lift-to-drag ratio $\left(\mathrm{W} / \mathrm{A}=15, \mathrm{C}_{\mathrm{W}} / \sigma=0.14\right)$.

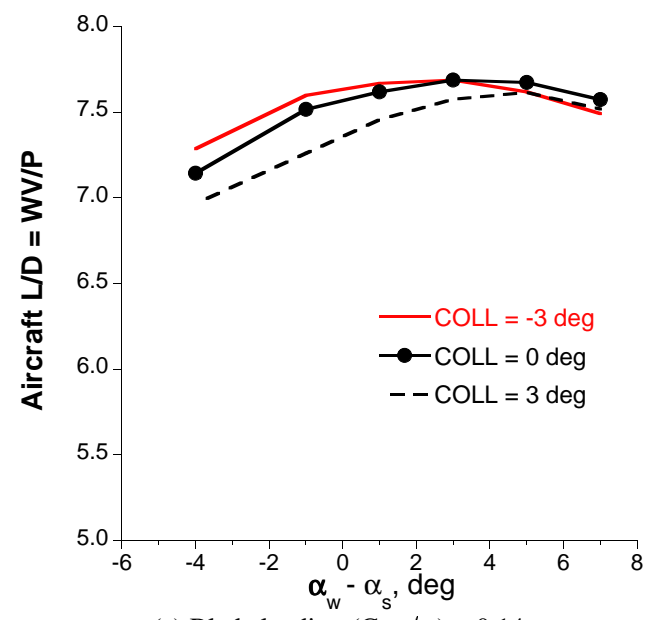

(a) Blade loading $\left(\mathrm{C}_{\mathrm{W}} / \sigma\right)=0.14$

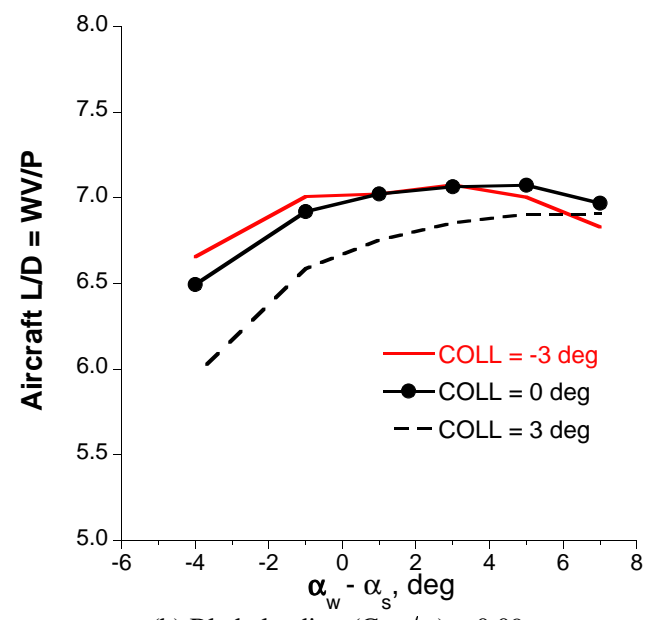

(b) Blade loading $\left(\mathrm{C}_{\mathrm{W}} / \sigma\right)=0.09$

Fig. 8 Effect of blade loading on aircraft lift-to-drag ratio $(\mathrm{W} / \mathrm{A}=15, \mathrm{~W} / \mathrm{S}=100)$. 


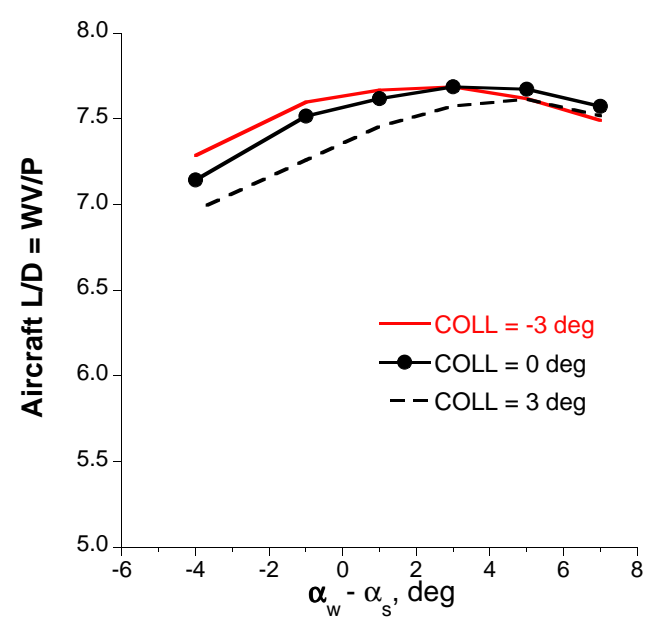

(a) Disk loading $(\mathrm{W} / \mathrm{A})=15$

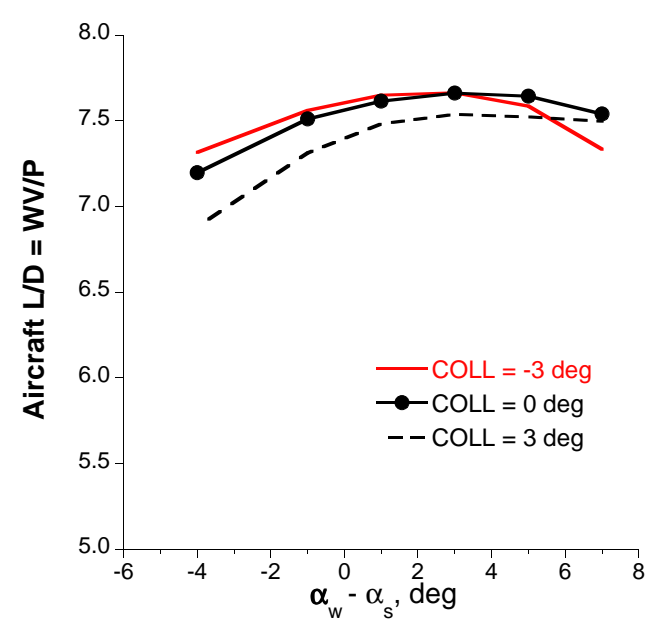

(b) Disk loading $(\mathrm{W} / \mathrm{A})=12$

Fig. 9 Effect of disk loading on aircraft lift-to-drag ratio $\left(\mathrm{C}_{\mathrm{W}} / \sigma=0.14, \mathrm{~W} / \mathrm{S}=100\right)$.

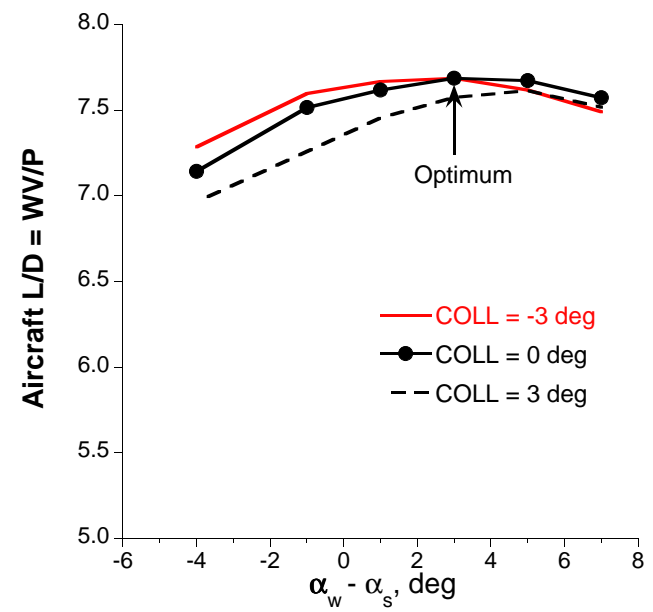

(a) Aircraft lift-to-drag ratio

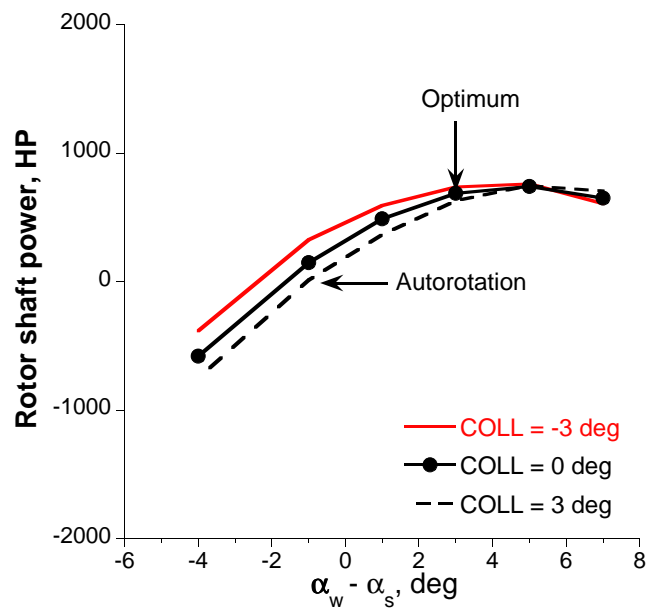

(b) Rotor shaft power

Fig. 10 Rotor shaft power $\left(\mathrm{W} / \mathrm{A}=15, \mathrm{C}_{\mathrm{W}} / \sigma=0.14, \mathrm{~W} / \mathrm{S}=100\right)$. 


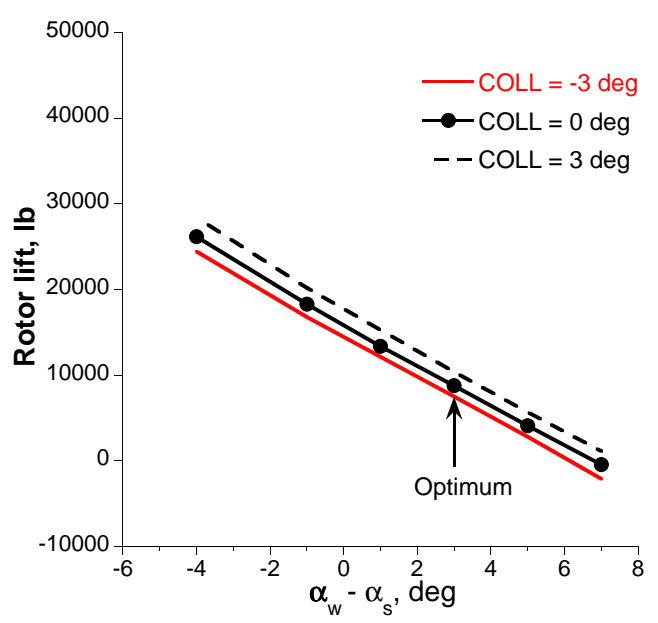

(a) Rotor lift

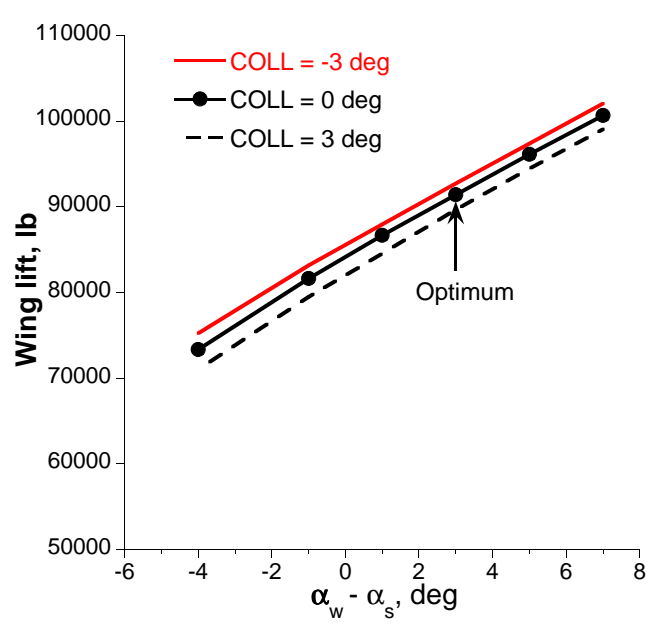

(b) Wing lift

Fig. 11 Optimum lift sharing $\left(\mathrm{W} / \mathrm{A}=15, \mathrm{C}_{\mathrm{W}} / \sigma=0.14, \mathrm{~W} / \mathrm{S}=100\right)$.

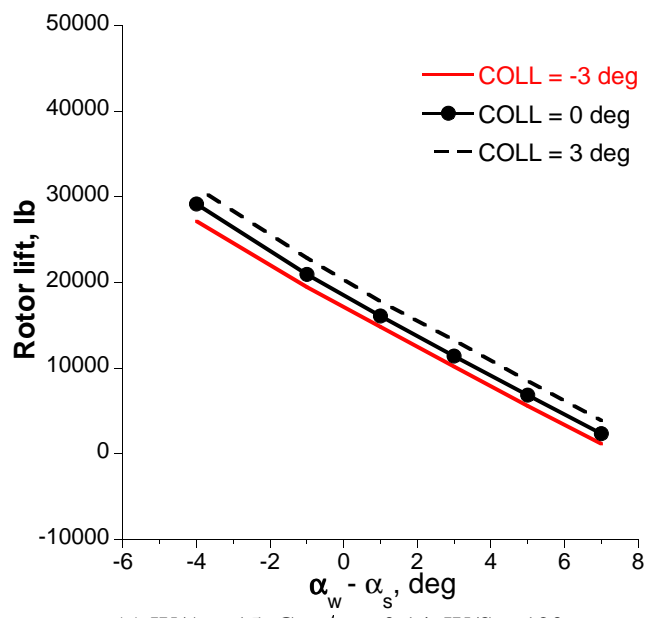

(a) $\mathrm{W} / \mathrm{A}=15, \mathrm{C}_{\mathrm{W}} / \sigma=0.14, \mathrm{~W} / \mathrm{S}=120$

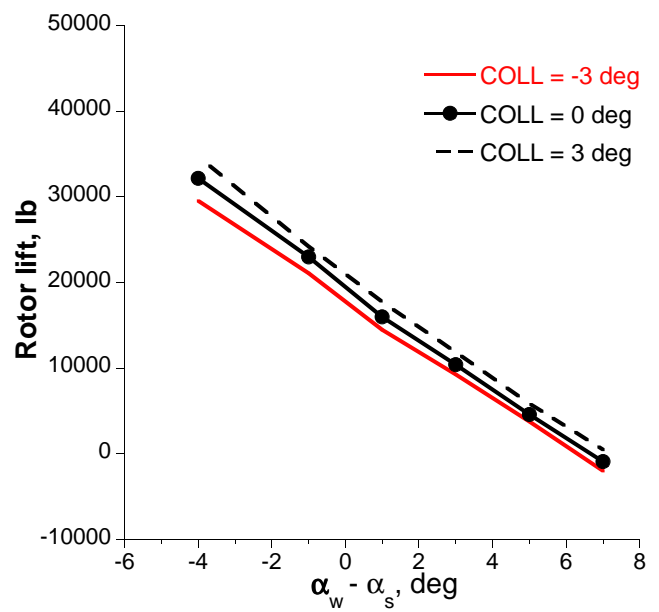

(b) $\mathrm{W} / \mathrm{A}=15, \mathrm{C}_{\mathrm{W}} / \sigma=0.09, \mathrm{~W} / \mathrm{S}=100$

Fig. 12 Rotor lift variation. 


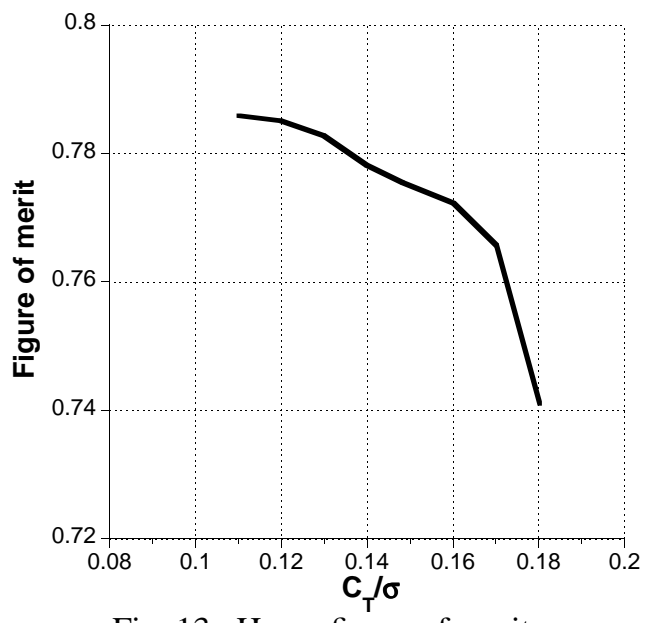

Fig. 13 Hover figure of merit.

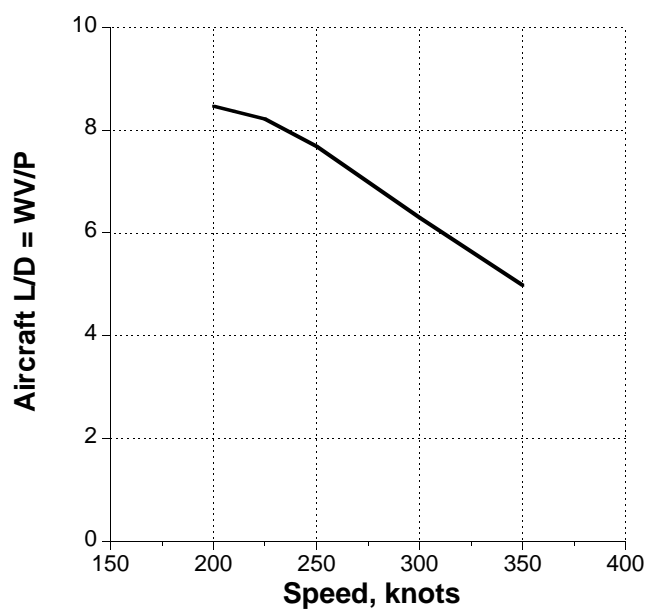

Fig. 14 Aircraft lift-to-drag ratio.

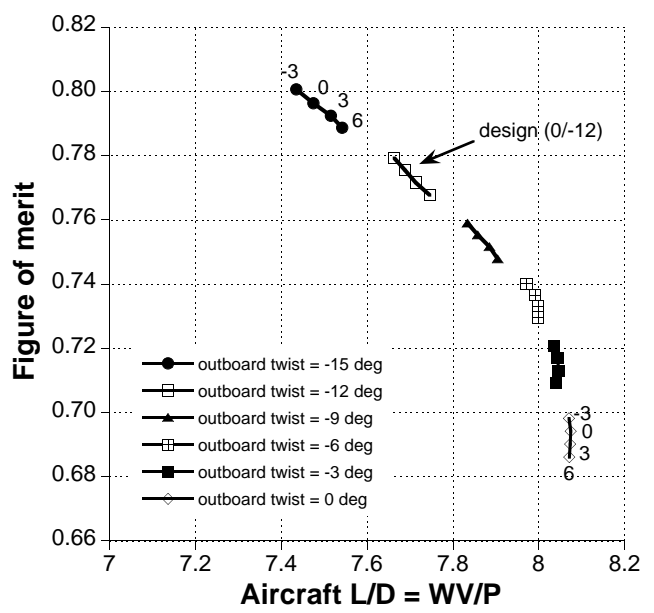

Fig. 15 Effect of blade twist on performance (inboard twist $=-3,0,3$, and $6 \mathrm{deg}$ ).

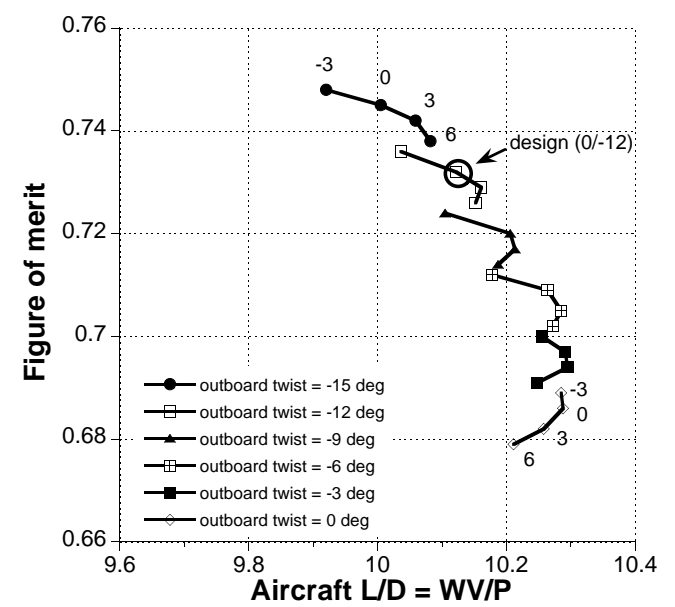

Fig. 16 Effect of blade twist on performance of LCTC (inboard twist $=-3,0,3$, and 6 deg) [Ref. 2].

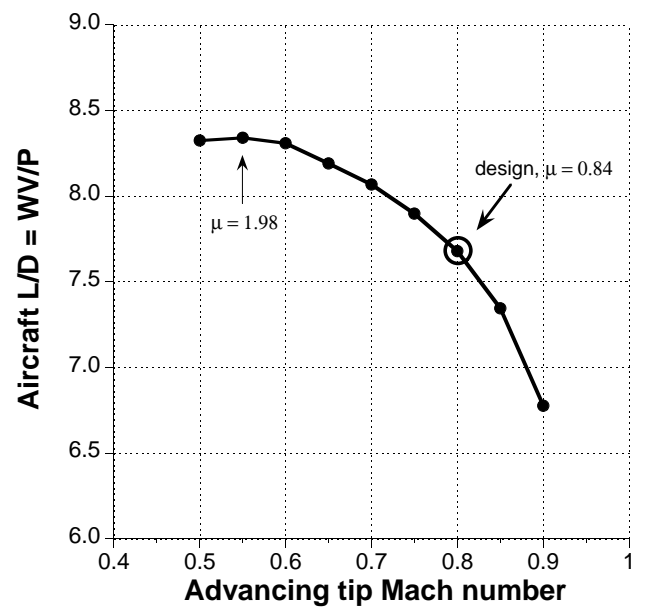

Fig. 17 Effect of tip speed on performance.

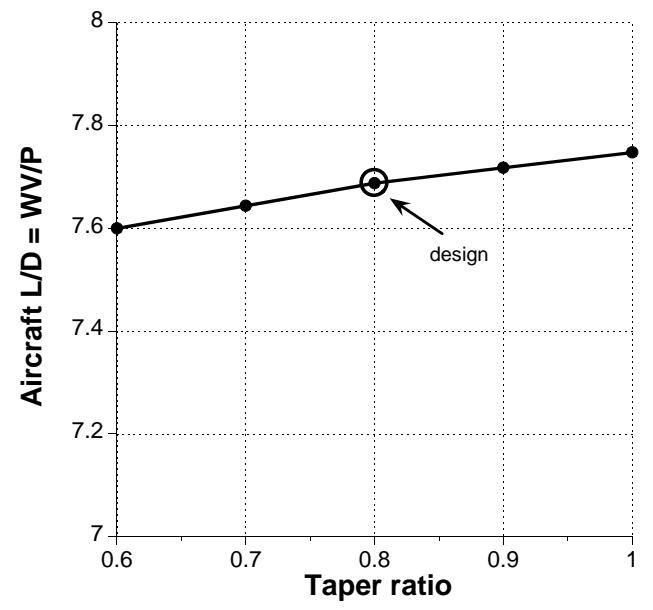

Fig. 18 Effect of blade taper on performance. 


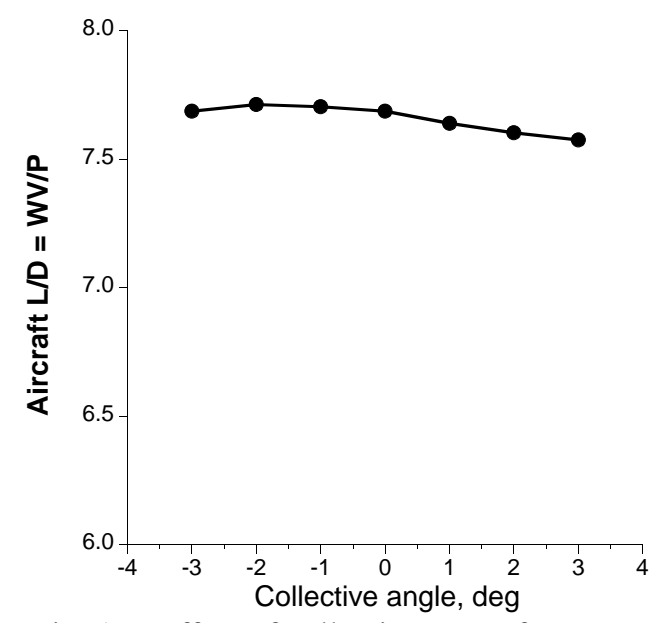

Fig. 19 Effect of collective on performance.

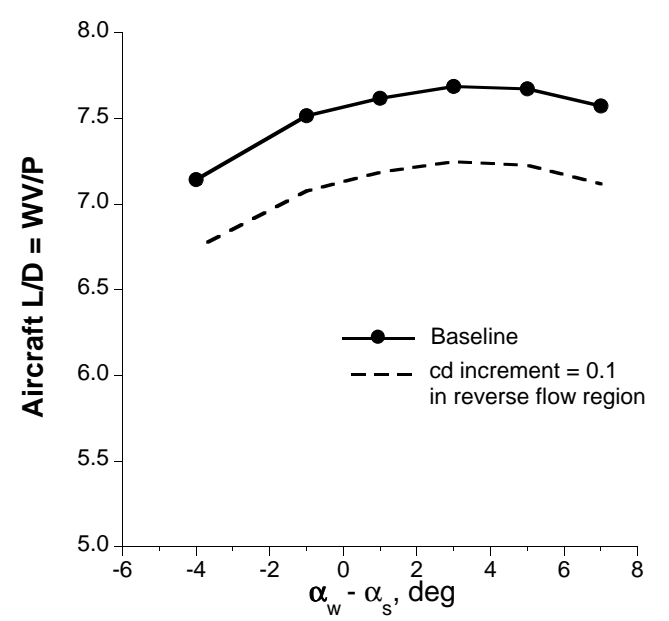

Fig. 20 Effect of airfoil drag on performance.

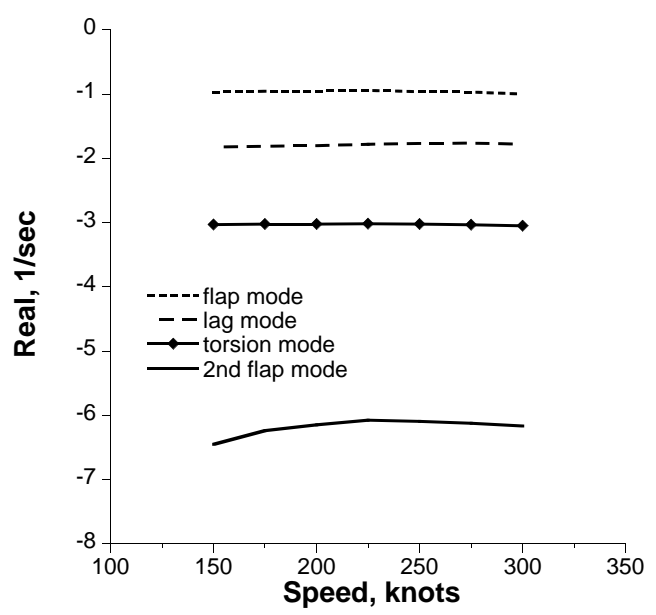

Fig. 21 Cruise stability.

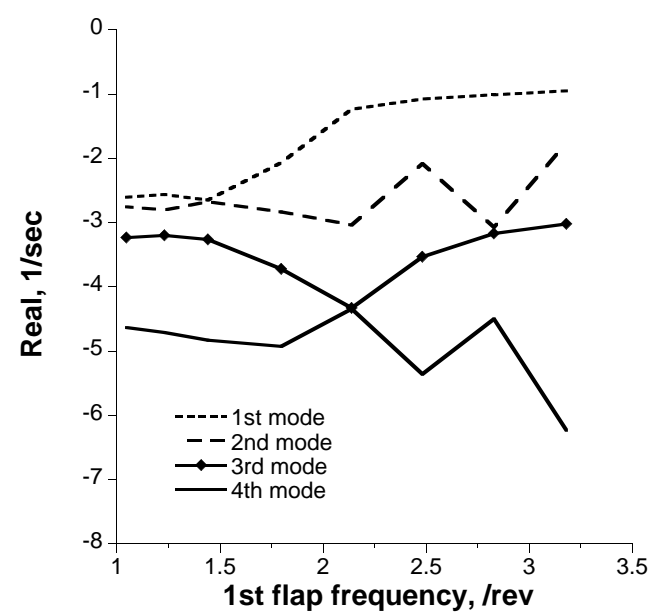

(a) First fhp frequency change

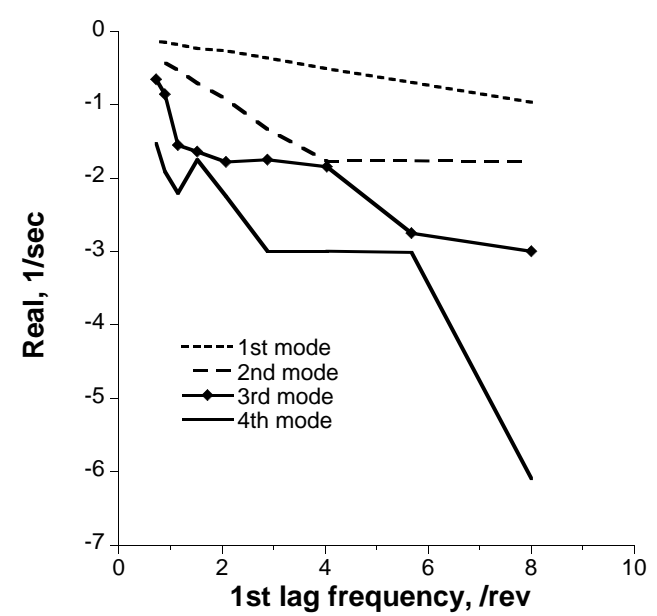

(b) First lag frequency change

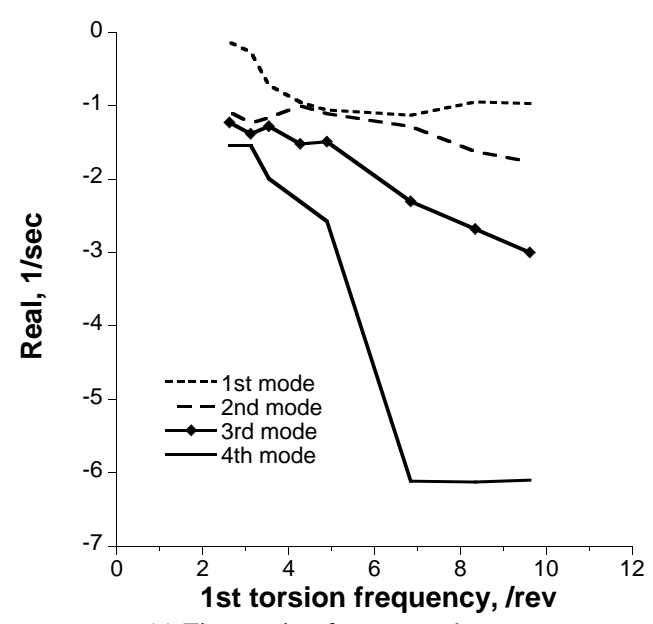

(c) First torsion frequency change

Fig. 22 Stability with blade frequency change for baseline aircraft at 250 knots. 


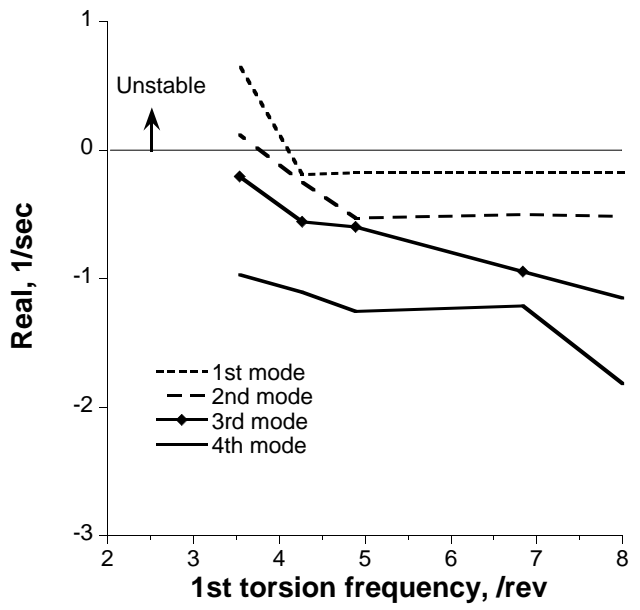

(a) Stiff in-plain rotor $\left(v_{\zeta}=1.14 / \mathrm{rev}\right)$

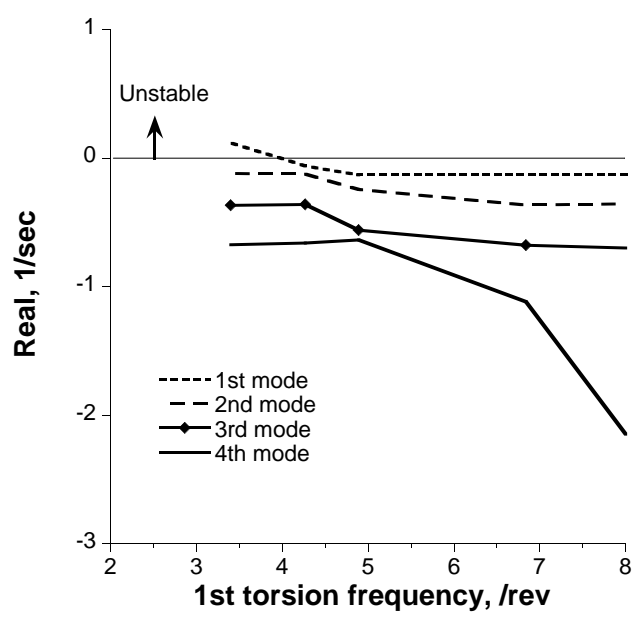

(b) Soft in-plain rotor $\left(v_{\zeta}=0.71 / \mathrm{rev}\right)$

Fig. 23 Stability with torsion frequency change for nominal articulated rotor $\left(v_{\beta}=1.05 / \mathrm{rev}\right)$ at 250 knots.

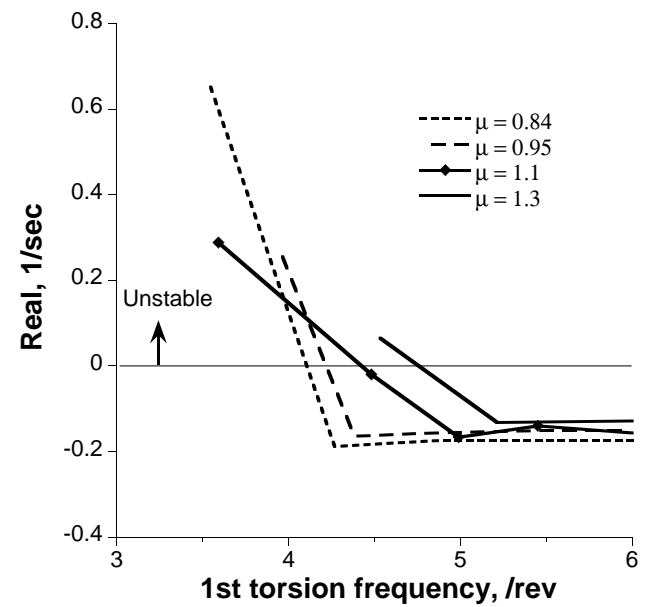

(a) Stiff in-plain rotor $\left(v_{\zeta}=1.14 / \mathrm{rev}\right)$

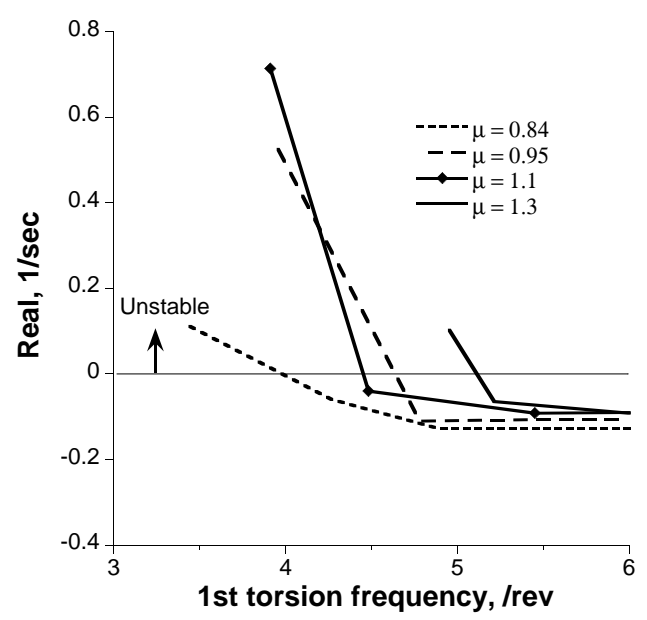

(b) Soft in-plain rotor $\left(v_{\zeta}=0.71 / \mathrm{rev}\right)$

Fig. 24 Stability boundary with torsion frequency change for nominal articulated rotor $\left(v_{\beta}=\right.$ $1.05 / \mathrm{rev}$ ) at 250 knots with different rotor RPM. 


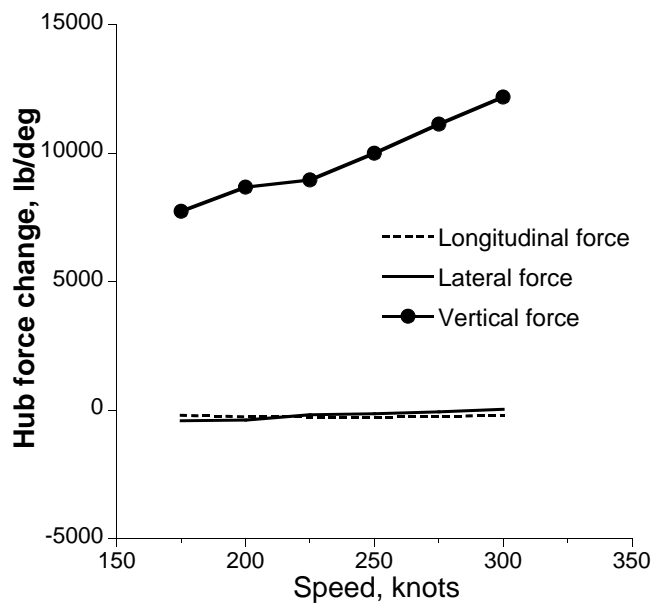

(a) Hub force change w.r.t. collective

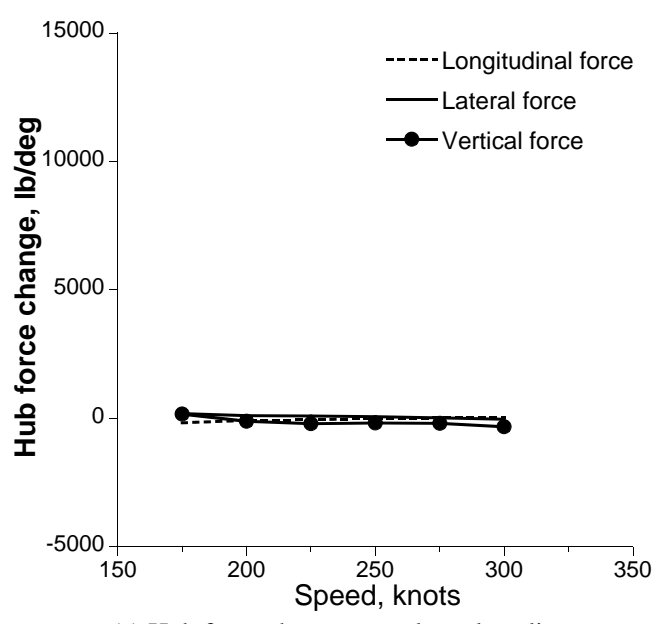

(c) Hub force change w.r.t. lateral cyclic

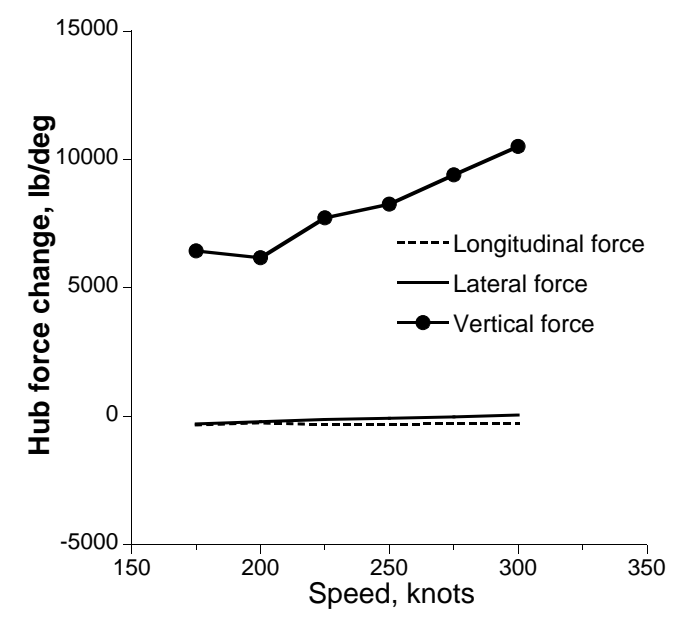

(e) Hub force change w.r.t. longitudinal cyclic

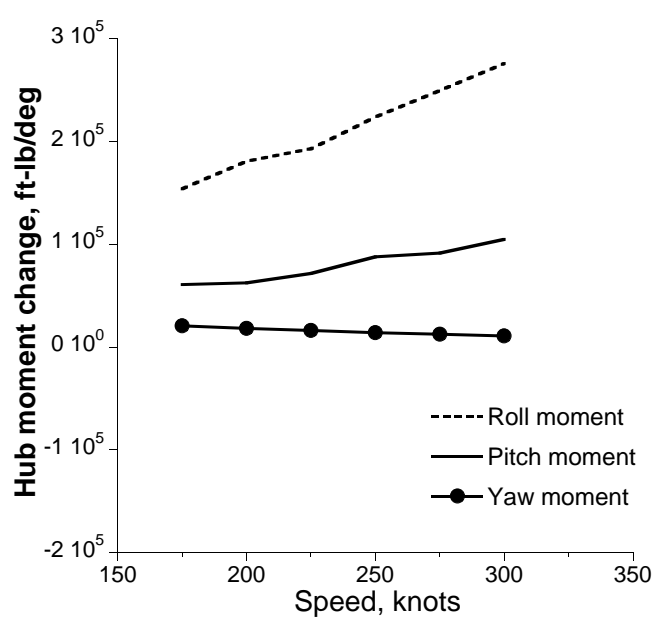

(b) Hub moment change w.r.t. collective

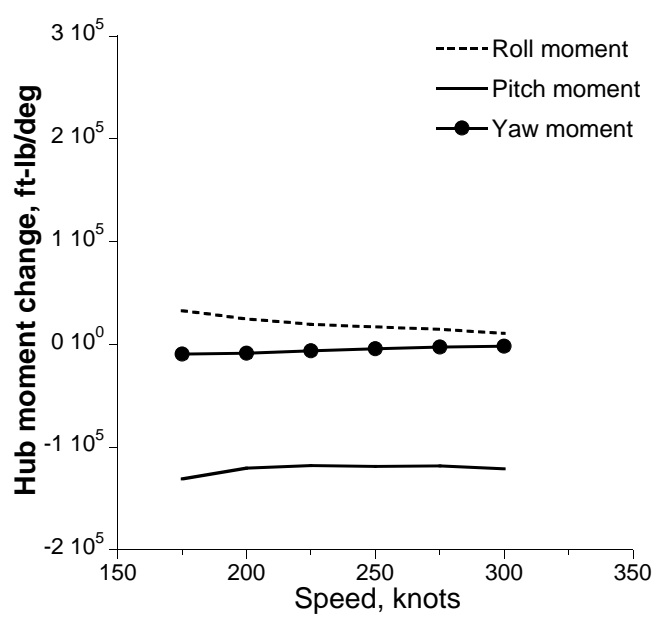

(d) Hub moment change w.r.t. lateral cyclic

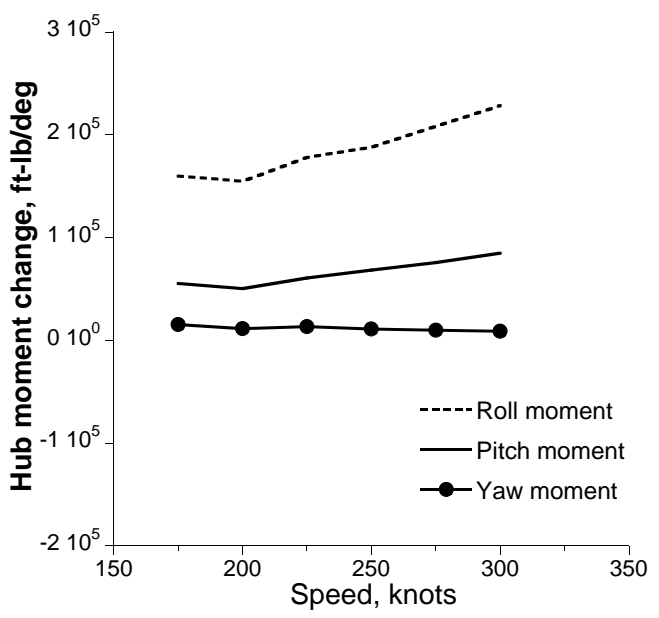

(f) Hub moment change w.r.t. longitudinal cyclic

Fig. 25 Hub load change w.r.t. controls. 